\title{
Development of a Kind of Mine Staff Management System
}

\author{
Wenlin Chen ${ }^{1}$, Baosong $\mathrm{Liu}^{2}$, Shiwei Sun ${ }^{2, \text { a }}$, Lina $\mathrm{Hao}^{2, \mathrm{~b}}$ \\ ${ }^{1}$ School of Resource and Civil Engineering, Northeastern University, China \\ ${ }^{2}$ School of mechanical Engineering and Automation Northeastern University, China \\ asunshiweipp@163.com, 'bhaolina@ise.neu.edu.cn
}

Keywords: RFID, GIS, Mine staff management system

\begin{abstract}
Designing the mine staff management system based on the RFID technology and GIS technology. The personnel ID information can be collected by the locating substation and transmitted to monitor center by the wireless network and cables. User's personnel ID information which is collected by the locating substation can be used to check the staff attendance and offer the rescuer some information with the trapped victims.
\end{abstract}

\section{Introduction}

The secure producing situation of the coalmine is about the people's life and property's safety, the central committee and all levels of governments correlation department give highly takes with vigorously to support. In general, the present secure producing situation of the coalmine has continued to tend toward relaxation through constant efforts, due to the various causes like the weak basis, the secure producing situation of the coalmine is very grim ${ }^{[1]}$. According to statistics, over the past few years, the annual death toll of the coalmine accidents have averaged about 5 thousands, among so many accidents, 80 percent is gas accident. So enhancing the inner staff management play a key role in preventing gas accident from occurring in the colliery. At present, the management of worker underground is inconvenience. The Persons distributing information who are working in underground coal mines are not monitored effectively by administrators. Once accident occurs, rescue is inefficient because of not enough information of the trapped coal miners ${ }^{[2]}$.

We have analyzed some recent serious accidents which happened in coal mines, and find some features as follows:

(1) There is poor communication between the managers and the persons in underground workplace of coal mine;

(2) The manager staff in the office can't know the situation of the people in the underground in time;

(3) Once accident takes place, rescuers can't confirm where the victim is in trouble, it will be obstruction to the rescue.

In order to suitably deal with the relation between safety and production, and accurately perform safety supervision and people management, we have developed the mine staff management system.

\section{Study on Architecture of Mine Staff Management System}

The System's Functional Definition and the Principle of Design. Mine staff management system is a comprehensive management system involves computer software, data base, electronic circuit, safety power supply, data communication and RFID and so on, so it makes full preparation in stability, reliability and the anti-interference. 
In the design and implementation of the mine staff management system, several issues such as cost, universal performance, and complicated circumstance are taken into consideration, and then give the design of mine staff management system based on RFID system consist of many card reader.

This system has following functions:
A. People and vehicle position checking and tracking;
B. Demography and attendance;
C. The management for safety monitoring;
D. Work overtime alarm and management;
E. Data statistics, historical data query and tracing curves browse;
F. Specific regions management;
G. Underground worker's map display function;
H. Information sharing with network.

The Systemic Constitution and the Working Principle. Mine staff management system consists of the facilities on the ground and the underground equipment.

The facilities on the ground are composed primarily of monitor host, transport interface, switchboard, printer, the lightning conductor and so on.

The underground equipment is composed primarily of card reader, tag, BFDZ-Z2A (N) power supply, explosion-proof power supply boxes and so on. The tag features low power and high performance, upgrade easily, anti-jamming and excellent security. Tag sends out continuing RFID digital signal when being used. Card reader is used for receiving data of tag, sensor, and other Wireless Repeater and transmitting the data which have been processed to the other Repeater, and finally the data are transported to the locating substation by the means, then the data are transported to the monitor host by FSK network ${ }^{[3]}$. At the same time, the card reader receives the signal from the tag and the relay station, then converts it into digital information and stores the digital code and receive time on the data base; Finally, These data are transmitted to the host computer through cables.

The working principle of system:

First of all, fixed card readers, power supplied by the monitoring station, specific quantities and locations depending on the actual working conditions and the objective should be installed in the mine tunnels and passages where the crews pass through.

Card readers, combined wire and wireless allocation, will be connected to the computers in the ground control center by cable, optical fiber and wireless network.

As for workers, an electronic tag has to be placed in their belongings, when workers go down into the tunnel and approach to anyone of the signal transceivers placed nearby, the card reader will receive a signal and then send the corresponding signal to the computer in the control center. Specific information, such as name of the worker, location and time will be acquired and displayed on the main interface of the software in the control center; the administrator will obtain the working status of the specific workers or vehicles by the location displayed on the monitor.

What's more, the activity of the personnel for a period of time will be received.

Attendance sheets and work condition sheets can be sorted out according to the activity record. Once there happens an accident, the locations and workers involved in will be easily discerned based on the information supplied by the system. Besides, special detector can be used to make further conformation so as to improve the rescue efficiency greatly ${ }^{[4,5]}$. 
The systemic constitution as fig. 1:

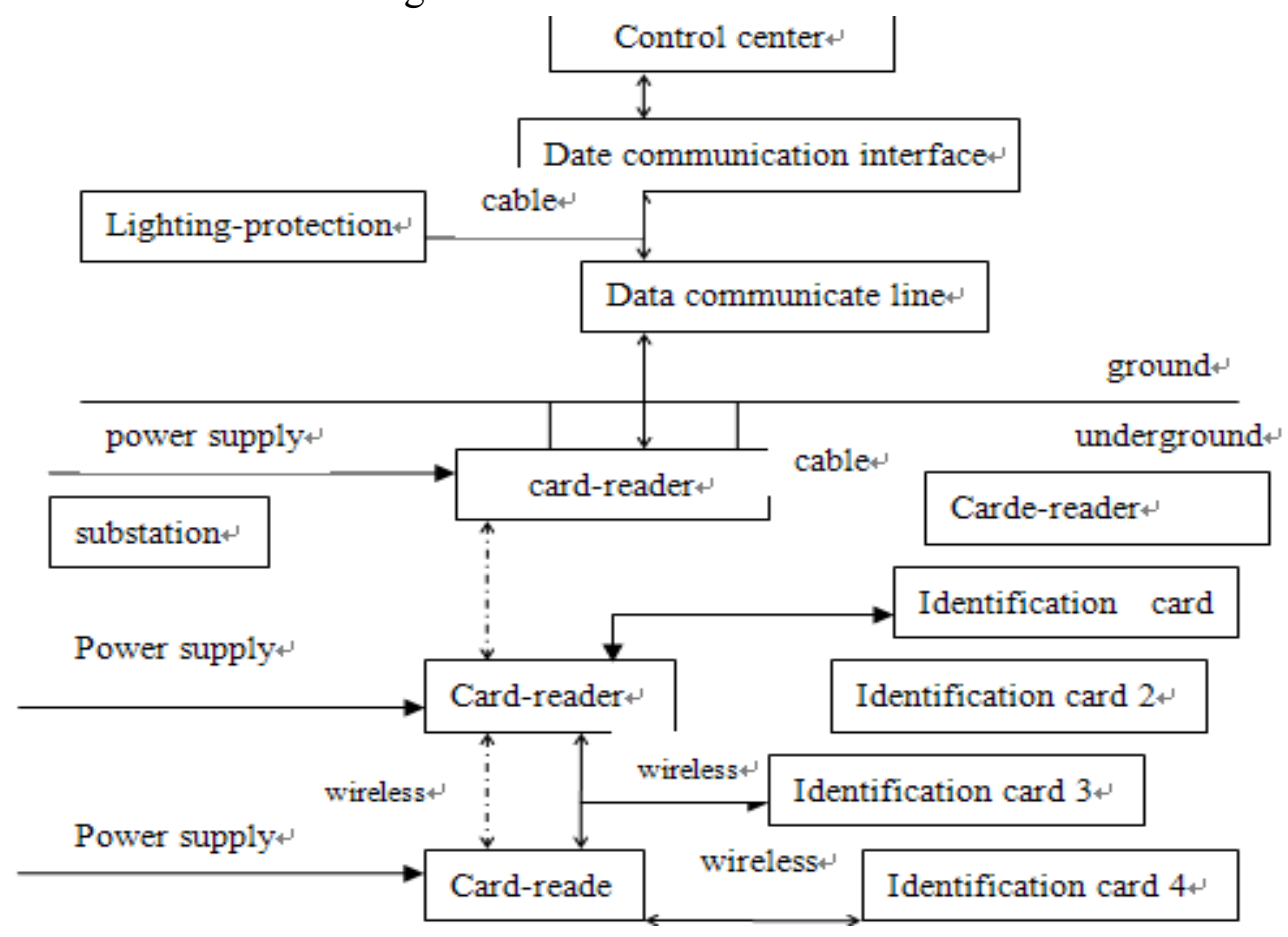

Fig. 1. Mine staff management system component plot

\section{Implemented with Technologies}

The Frameworks of Underlying Technologies. The underlying technology uses the RFID technology, adopts new security design, and can realize reliable full-duplex communication. It features far operating distance, environmental adaptability, excellent security, and users can adjust the identification distance according to actual situations in order to make identification more accurately ${ }^{[6]}$.

Underlying system is composed by three major parts: the locating substation, wireless card reader and tag. The location substation is made up of $18 \mathrm{~V}$ power supply, I/O interface and the power management, etc.; wireless card reader is made up of CPU, wireless communications, I/O interface, the power management and so on; tag is made up of CPU, wireless communications, I/O interface and so on.

Technical Frame of the Application System. As shown in Fig. 2, the entire application system is composed by three major parts: 1) data base; 2) Monitoring services; 3) management services.

Data base is used to store data of the application system ${ }^{[7]}$.

Monitoring system: Fulfils the data exchange of the service management system and hardware network system, and measure of the network equipment hardware automatically.

Service management system: Main function is target location, special region management, emergency rescue, attendance management, typing lists, GIS software and so on.

\section{The Main Technique.}

(1) Low power wireless communication technologies of international trends;

(2) Full-duplex communication wireless communication;

(3) Industry Control System Network technology (Using special topology framework which are FSK dominated);

(4) Comprehensive management software system based on GIS;

(5) Large scale data analysis and disposal technology. 


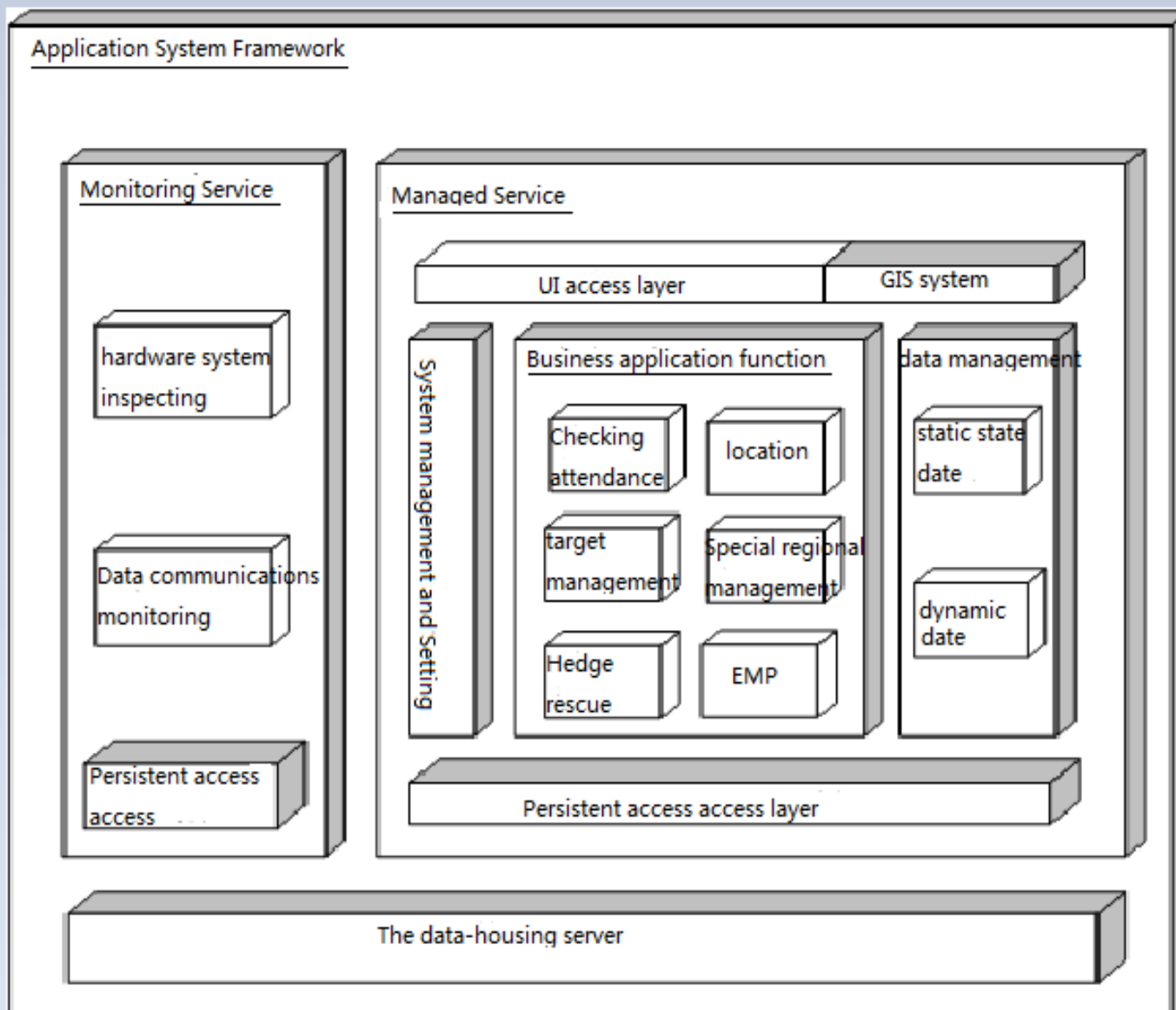

Application System Framework Schematic plot

Fig. 2. Application system framework schematic plot

Comparison with the Same Sort of Product. There are many some products on market, for example, KJ214 and KJ376, etc. But the system has a demonstrable difference, which adopted the mixed way that GIS combines with RFID ${ }^{[8,9]}$. Compared to the same products on markets:

Table 1 The system compare with the like product in market

\begin{tabular}{|c|c|c|}
\hline Function & The system personnel management systems & Similar product \\
\hline Staff attendance & Have & Have \\
\hline $\begin{array}{l}\text { Mine personnel } \\
\text { positioning }\end{array}$ & Precise positioning of no-blind-area & Finite point positioning method \\
\hline $\begin{array}{l}\text { Accuracy of } \\
\text { positioning }\end{array}$ & $\pm 10 \mathrm{~m}$ & $\pm 25 \mathrm{~m}$ \\
\hline $\begin{array}{l}\text { Labeled card } \\
\text { battery }\end{array}$ & $\begin{array}{c}\text { Low power design, long battery operating } \\
\text { lifetime. }\end{array}$ & $\begin{array}{l}\text { Low power design, battery } \\
\text { operating lifetime. }\end{array}$ \\
\hline $\begin{array}{c}\text { Two-way } \\
\text { communication } \\
\text { function }\end{array}$ & Powerful 2-way messaging capabilities & $\begin{array}{l}\text { One-way communication or } \\
\text { simple duplex way }\end{array}$ \\
\hline Alarm function & $\begin{array}{l}\text { The coal miners can give alarm by } \\
\text { pressuring the card's button, and receive the } \\
\text { information of any disaster which the } \\
\text { control center sends. }\end{array}$ & $\begin{array}{l}\text { Not have alarming function or } \\
\text { very simple }\end{array}$ \\
\hline
\end{tabular}




\begin{tabular}{|c|c|c|}
\hline $\begin{array}{c}\text { Graphics display } \\
\text { function }\end{array}$ & $\begin{array}{c}\text { GIS's powerful map processing functions } \\
\text { and dynamic positions display }\end{array}$ & Not have or simple \\
\hline $\begin{array}{c}\text { System network } \\
\text { architecture }\end{array}$ & $\begin{array}{c}\text { Using special topology framework in which } \\
\text { FSK is dominated, it has features such as } \\
\text { large capacity, long data-transmitting } \\
\text { distance, fast speed, easy to extend and } \\
\text { update, etc. }\end{array}$ & $\begin{array}{c}\text { Have difficulty in network } \\
\text { grouping. }\end{array}$ \\
\hline $\begin{array}{c}\text { System } \\
\text { installation and } \\
\text { upgrade }\end{array}$ & $\begin{array}{c}\text { System network adopts the design mixed } \\
\text { with the wired mode and wireless mode, and } \\
\text { it is flexible to build up, low cost, simple } \\
\text { structure, so it is the perfect setting for any } \\
\text { mine }\end{array}$ & $\begin{array}{c}\text { Not fit the complicated mine, } \\
\text { expensive, and difficult } \\
\text { construction. }\end{array}$ \\
\hline
\end{tabular}

\section{Test Result}

Build the application platforms and design the control software in accordance with the above method. This software adopts the module structure to ensure easy maintenance.

As shown in fig. 3 is main images of the control system:

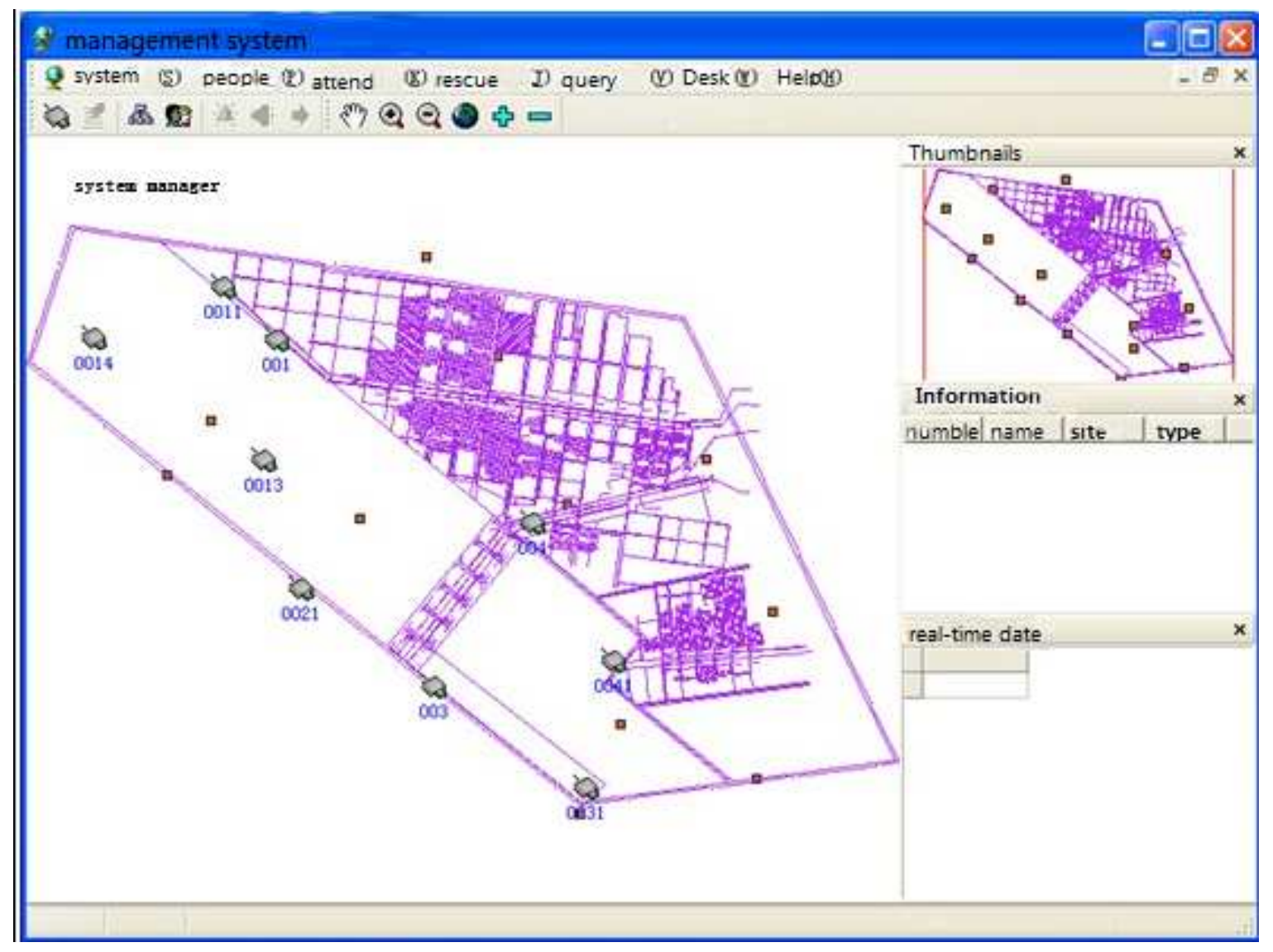

Fig. 3. Main images of the control system 
As shown in fig. 4 is the people's real-time location date:

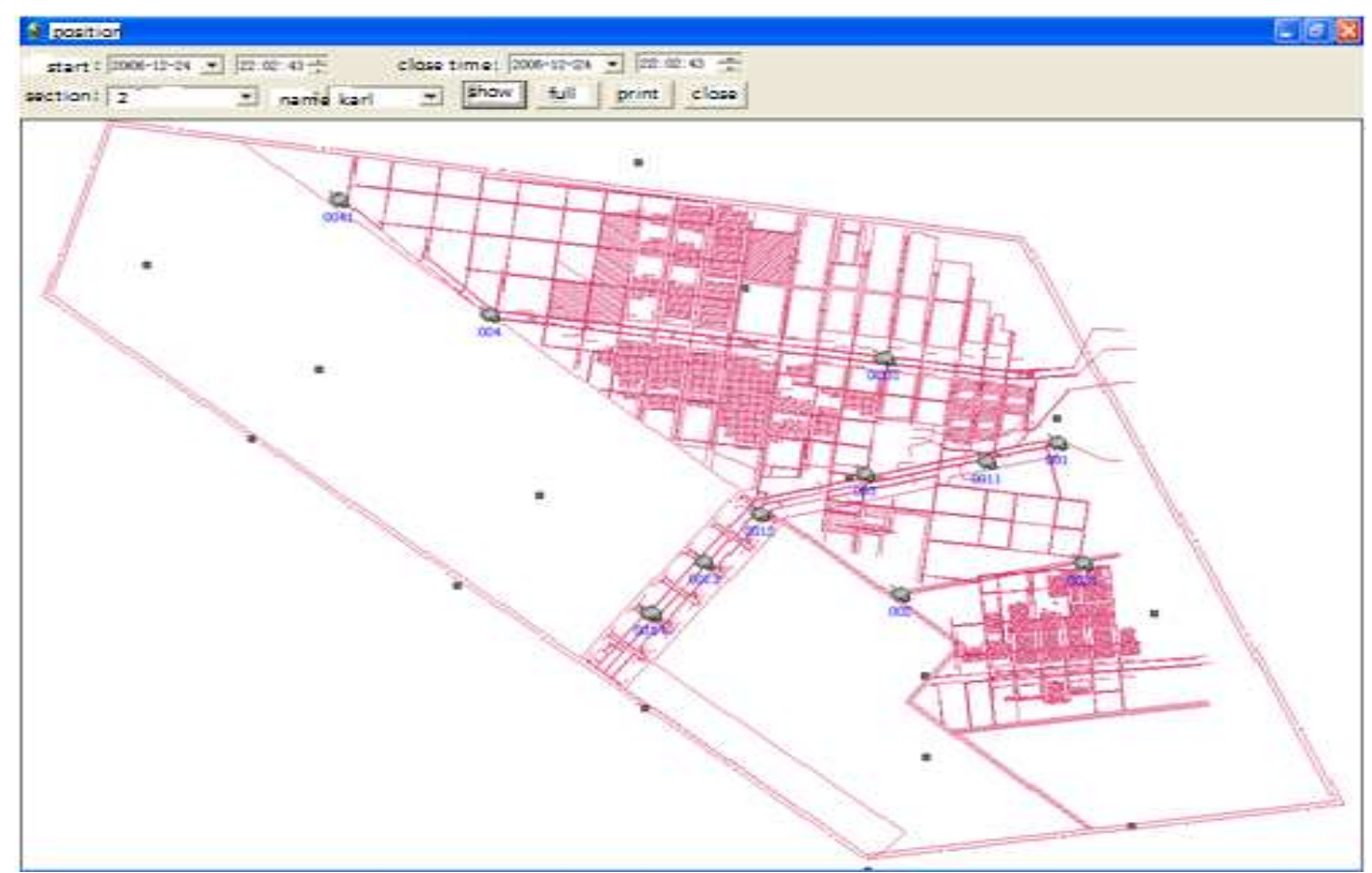

Fig. 4. UI images of the people's real-time location date

\section{Summarize}

The management system uses the RFID technology to locate the worker, and the network is seted up with wireless or cables. It realizes the date communication between the card reader and host by the FSK bus inspection, makes use of the comprehensive software system which based on GSI to display, and manages relevant information of the people and devices. This system is of great practical value.

\section{References}

[1] Liang Haihui, Being in lost of the enterprise community responsibility and frequent occurrence of accidents in coal mines. Economy Management, 2006, (05):73-75.

[2] Guo Yanli, South Africa mining industry RFID Mine application examples, AUTOMATIC IDENTIFICATION TECHNOLOGY \& APPLICATION , 2005, (05):48-51.

[3] Zeng Wei, Li Xiaogang, Zheng Que, The design and realization of KJ208 Underground Mine Personnel location tracking management system, Coal mine safety, 2006,(11):47-49.

[4] Zhao Cong, The Research and Development of Underground Mine Personnel Orientation and Management Software System, Hunan University, Changsha,2009,(10):30-60

[5] Chen Hui, RFID System Utilization to Achieve Positioning Management System of Personnel under Mine, Shanghai Jiaotong University, Shanghai,2008,(08),15-28

[6] Rao Siqiang, The Research and Design of Managerial System about Mine Production Safety Base on RFID and GIS, Central South University, Changsha,2009,(05),20-37

[7] Chen Hualiang, Principle and Application of Web GIS Based on the Open Source Platform, Changan university, Xian,2009,(10),18-34

[8] The State Bureau of Coal Mine Security Supervision, An analysis of coal mine work safety situation and countermeasures for improvement, Beijing, 2006.

[9] LI Jingyan, CHEN Yong, Wang Zhijian, Web Services-based Framework for Distributed GIS, Computer \& Information Engineering College of Hohai University; Nanjing 210098. 